\title{
Radiation Risks in Cis-Lunar Space for a Solar Particle Event Similar to the February 1956 Event
}

\author{
Fahad A. Zaman * (D) and Lawrence W. Townsend \\ Department of Nuclear Engineering, University of Tennessee, Knoxville, TN 37996, USA; ltownsen@vols.utk.edu \\ * Correspondence: fzaman@vols.utk.edu
}

Citation: Zaman, F.A.; Townsend, L.W. Radiation Risks in Cis-Lunar Space for a Solar Particle Event Similar to the February 1956 Event. Aerospace 2021, 8, 107. https:// doi.org/10.3390/aerospace8040107

Academic Editor: Pierre Rochus

Received: 24 March 2021

Accepted: 12 April 2021

Published: 14 April 2021

Publisher's Note: MDPI stays neutral with regard to jurisdictional claims in published maps and institutional affiliations.

Copyright: (c) 2021 by the authors. Licensee MDPI, Basel, Switzerland. This article is an open access article distributed under the terms and conditions of the Creative Commons Attribution (CC BY) license (https:// creativecommons.org/licenses/by/ $4.0 /)$.

\begin{abstract}
Solar particle events (SPEs) can pose serious threats for future crewed missions to the Moon. Historically, there have been several extreme SPEs that could have been dangerous for astronauts, and thus analyzing their potential risk on humans is an important step towards space exploration. In this work, we study the effects of a well-known SPE that occurred on 23 February 1956 on a mission in cis-Lunar space. Estimates of the proton fluence spectra of the February 1956 event were obtained from three different parameterized models published within the past 12 years. The studied geometry consists of a female phantom in the center of spherical spacecraft shielded by aluminum area densities ranging from 0.4 to $40 \mathrm{~g} \mathrm{~cm}^{-2}$. The effective dose, along with lens, skin, blood forming organs, heart, and central nervous system doses, were tallied using the On Line Tool for the Assessment of Radiation In Space (OLTARIS), which utilizes the High Z and Energy TRansport code (HZETRN), a deterministic radiation transport code. Based on the parameterized models, the results herein show that thicknesses comparable to a spacesuit might not protect against severe health consequences from a February 1956 category event. They also show that a minimum aluminum shielding of around $20 \mathrm{~g} \mathrm{~cm}^{-2}$ is sufficient to keep the effective dose and critical organ doses below NASA's permissible limits for such event. In addition, except for very thin shielding, the input models produced results that were within good agreement, where the doses obtained from the three proton fluence spectra tended to converge with slight differences as the shielding thickness increases.
\end{abstract}

Keywords: space travel; astronauts; solar particle event; radiation

\section{Introduction}

In the mid-1950s, at the dawn of the modern space program, an enormous solar flare, accompanied by a large flux of very energetic charged particles, mainly protons, occurred on 23 February 1956. A plethora of scientific observations of this event were available due to preparations for the upcoming International Geophysical Year in 1957. At 0331 UT, the optical flare was observed and reached its peak intensity increase shortly thereafter at 0342 UT. Associated cosmic ray intensities were detected by various neutron monitors on the ground shortly thereafter at 0340-0350. Neutron monitor increases at Leeds, UK, exceeded $4500 \%$ between 0345 and 0350 , indicating the arrival of secondary neutrons produced by highly relativistic protons impinging on Earth's atmosphere. A thorough overview of the history of this event can be found in a publication by [1]. A comprehensive model of the particle spectrum from the event was quickly developed by [2]. Potential biological effects on humans in space were also quickly recognized by [3].

During the Apollo era an event occurred in August 1972, between the Apollo 16 and 17 missions that had the largest fluence of protons ever measured in a solar particle event. Fortunately, the particle flux decreased rapidly with increasing particle energies, resulting in a "soft" spectrum, one that could be shielded against with even moderate amounts of spacecraft shielding. Concerns, however, did arise as to how large could an event occur that would significantly impact a human space mission (e.g., [4,5]). Clearly, one with a very energetic proton energy spectrum ("hard" spectrum) would be the most difficult to shield against. 
Over the past two decades, evidence of several extremely large historic solar events, much stronger than any observed in the modern space era, have been discovered (e.g., [6-9]). Although the initial results in [6] suggested that a large, energetic proton fluence accompanied the Carrington event of 1859, it was later determined not to be the case [10]. However, convincing evidence for other extremely large and very energetic solar particle events was present for other time periods [11]. At present it is known that extreme solar particle events did occur in 774/775 AD, 993/994 AD, and $660 \mathrm{BC}$ [9]. Each event had a proton spectral hardness comparable to that of the 23 February 1956 event, with proton fluences more than order of magnitude higher. Ref. [12] have recently provided insight into the causes of the very high energy protons in the spectra for the 1956 and $774 \mathrm{AD}$ events. They suggest that these protons came from high-energy, impulsive events erupting on the Sun from the borders of the optimum connection region to Earth (W40-70 longitude on the Sun) and were accelerated by quasi-perpendicular shocks. Estimates of doses from the 774/775 AD event, using an earlier Band Fit parameterization of the 1956 event [13], scaled to the fluence of the 774/775 AD event, presented in [14], were reported by [15]. More recently, updated spectral parameters for the February 956 event spectrum, based upon the Band function [16], and another based upon a new parameterization using a modified Band function form [17] were published. In this work we compare radiation risk quantities for crew members exposed to the above-mentioned spectral representations characterized by the February 1956 category event. The crew members are assumed to be 40 -year females on a mission in cis-Lunar space, shielded by aluminum area densities ranging from 0.4 to $40 \mathrm{~g} \mathrm{~cm}^{-2}$ (representative of shielding for space suits to storm shelters).

\section{Computational Methods}

To calculate the risk from a February 1956 category event, three isotropic source terms were generated to provide a comparison between the different spectral estimates of the actual event: Band function by [13], Band function by [16], and a modified Band function by [17]. These spectra will be referred to as BF10, BF18, and U20, respectively. The Band function used in BF10 and BF18 is given by:

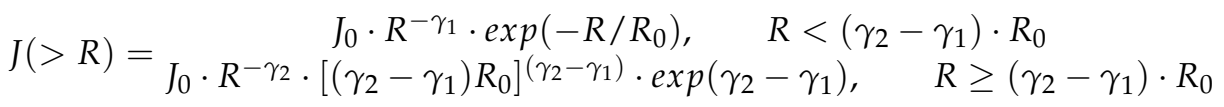

where $J(>R)$ is integral proton fluence in units of $\# / \mathrm{cm}^{2}$, and $R$ is the proton rigidity in units of GV, while $J_{0}, R_{0}, \gamma_{1}$, and $\gamma_{2}$ are fitting parameters provided in Table 1 for BF10 and BF18.

Table 1. Band fit parameters for the February 1954 event obtained from [13] for BF10 and [16] for BF18.

\begin{tabular}{lcccc}
\hline Band Function & $\boldsymbol{J}_{\mathbf{0}}\left(\# / \mathrm{cm}^{\mathbf{2}}\right)$ & $\boldsymbol{R}_{\mathbf{0}}(\mathrm{GV})$ & $\gamma_{\mathbf{1}}$ & $\gamma_{\mathbf{2}}$ \\
\hline BF10 & $8.79 \times 10^{8}$ & $3.21 \times 10^{-1}$ & 0.584 & 5.040 \\
BF18 & $1.75 \times 10^{8}$ & $5.66 \times 10^{-1}$ & 1.760 & 0.566 \\
\hline
\end{tabular}

The modified Band function for U20 is given by:

$$
\begin{aligned}
& J(>R)=\begin{array}{ll}
J_{1} \cdot R^{-\gamma_{1}} \cdot \exp \left(-R / R_{1}\right), & R<R_{b} \\
J_{2} \cdot R^{-\gamma_{2}} \cdot \exp \left(-R / R_{2}\right), & R \geq R_{b}
\end{array} \\
& R_{b}=\left(\gamma_{2}-\gamma_{1}\right) \cdot \frac{R_{1} \cdot R_{2}}{\left(R_{2}-R_{1}\right)} \\
& J_{1}=J_{2} \cdot R_{b}^{\gamma_{1}-\gamma_{2}} \cdot \exp \left(\gamma_{2}-\gamma_{1}\right)
\end{aligned}
$$


where $R_{1}=0.823 \mathrm{GV}, R_{2}=4.692 \mathrm{GV}, \gamma_{1}=1.822, \gamma_{2}=4.207, J_{2}=1.023 \times 10^{8} \# / \mathrm{cm}^{2}$, $J_{1}=1.4 \times 10^{8} \# / \mathrm{cm}^{2}$ and $R_{b}=2.38 \mathrm{GV}$ for the February 1956 event [17]. Figure 1 illustrates the integral energy spectra of the three source terms.

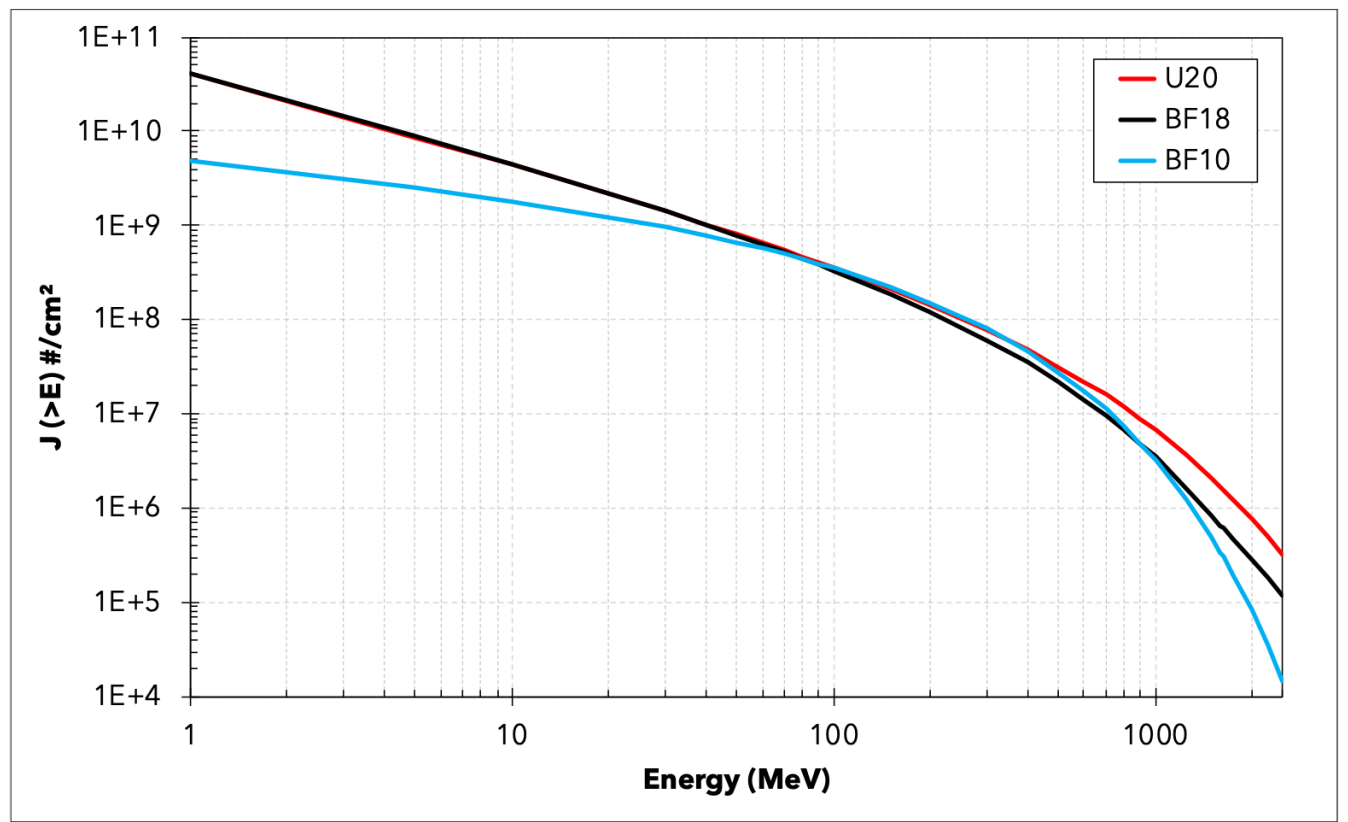

Figure 1. Proton fluence spectra for the February 1956 event generated using BF10, BF18, and U20.

These input spectra were transported using the On-Line Tool for the Assessment of Radiation In Space (OLTARIS). OLTARIS was developed by NASA Langley Research Center. It utilizes the High $Z$ and Energy TRansport (HZETRN) deterministic transport code to calculate various outputs of interest, including effective and organ doses. The geometry used in this work consists of a Computerized Anatomical Female (CAF) model placed in the center of spherical spacecraft with an aluminum shielding having areal densities of 0.4 , $5,10,20,40 \mathrm{~g} \mathrm{~cm}^{-2}$. For the same radiation field in thin shields, females have a radiation risk that is generally higher than males due to body mass and size differences, and thus the CAF model was chosen since it is more limiting.

OLTARIS calculates the organ or tissue averaged dose equivalent, $H_{T}$, in units of Sievert (Sv), by averaging target points in selected organs or tissues. Dose equivalent is obtained by multiplying the absorbed dose, D, in units of Gray (Gy), by a quality factor, $Q$, which is a factor dependent on the linear energy transfer (LET) along the incident particle track. The effective dose, E, in units of Sievert (Sv), from the solar particle event is obtained by averaging the dose equivalents from all modeled organs and tissues by the following expression:

$$
\sum w_{T} H_{t}
$$

where $w_{T}$ is the weighting factor of the organ or the tissue. Table 2 presents NASA's permissible limits of the effective dose for different female ages. These limits are based upon a 3\% Risk of Exposure Induced Death (REID) at the 95\% confidence limit [18], and depend on mission duration, the radiation environment, and sex of the crew member. 
Table 2. NASA's permissible effective dose limits for 1-year mission [18].

\begin{tabular}{cc}
\hline Age (year) & Effective Dose Limit (cSv) \\
\hline 30 & 60 \\
40 & 70 \\
50 & 82 \\
60 & 98 \\
\hline
\end{tabular}

The dose of organs of short-term concern, in units of Gray-Equivalent (Gy-Eq), are calculated using

$$
\mathrm{D}(\mathrm{Gy}-\mathrm{Eq})=\mathrm{D}(\mathrm{Gy}) \cdot \mathrm{RBE}
$$

where $R B E$ is the relative biological effectiveness, a factor that relates to the increased biological damage of the incident charged particle. For protons, the RBE factor is 1.5 . Table 3 presents NASA's permissible dose limits for selected organs [19]. These organs are lens, skin, blood forming organs (BFO), heart, and central nervous system (CNS).

Table 3. NASA's permissible dose limits for short-term or career non-cancer effects.

\begin{tabular}{lccc}
\hline Organ & 30-day & 1-year & Career \\
\hline Skin (cGy-Eq) & 150 & 300 & 600 \\
Heart (cGy-Eq) & 25 & 50 & 100 \\
Lens (cGy-Eq) & 100 & 200 & 400 \\
BFO (cGy-Eq) & 25 & 50 & N/A \\
CNS * (cGy) & 50 & 100 & 150 \\
\hline
\end{tabular}

${ }^{*}$ Units of cGy are used since the RBE for CNS damage is unknown.

\section{Results and Discussion}

\subsection{Effective Dose}

Figure 2 presents the effective dose results from the three scenarios studied in this work. At $0.4 \mathrm{~g} \mathrm{~cm}^{-2}, \mathrm{U} 20$ and BF18 values are close to each other, and above the limit for the 50-year old female, but below the limit for the 60 -year old ( $98 \mathrm{cSv}$ ). At the same thickness, the BF10 value lies between the limits for 30 and 40-year old females. At thicknesses of $5 \mathrm{~g} \mathrm{~cm}^{-2}$ and above, the effective dose obtained using the three spectra start to converge relative to each other, with all dose values being below the 30 -year old limit. Due to differences in parametrized models, the calculated risk of developing fatal cancer varies. For a 40-year female exposed to a February 1956 category event with $0.4 \mathrm{~g} \mathrm{~cm}^{-2}$ aluminum shielding, the effective dose is $89.7 \mathrm{cSv}$ for U20 and $87.9 \mathrm{cSv}$ for BF18. The corresponding Risk of Exposure-Induced Death (REID) point values for a 1-year mission are 3.5\% for U20 and $3.4 \%$ for BF18. However, the risk of death from fatal cancer at the $95 \%$ confidence level could be as high as $11.8 \%$ and $11.6 \%$ for U20 and BF18, respectively. For BF10, the effective dose $(67.1 \mathrm{~Sv})$ is slightly below the limit for a 40 -year old $(70 \mathrm{cSv})$, and the corresponding REID point value for a 1 -year mission is $2.9 \%$, but the REID at the $95 \%$ confidence level is $9.7 \%$. The elevated risk from acute radiation syndrome for some organs in the short-term is of the most significant concern, and will be addressed in the next section. 


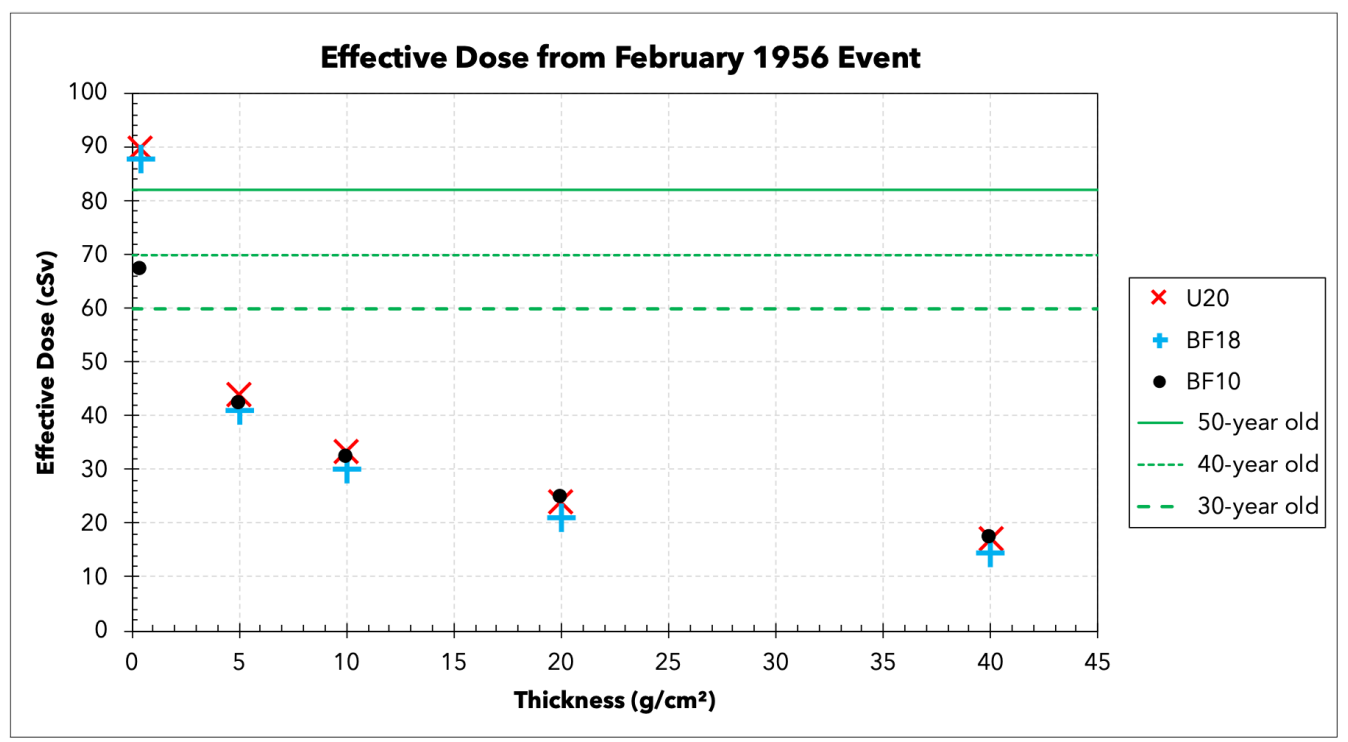

Figure 2. The effective dose from U20, BF18, and BF10 February 1956 event spectra for various aluminum thicknesses. NASA's permissible limits for 1-year mission for 30, 40, and 50-year old females are included in the plot. The dose limit for 60 -year old is above the maximum obtained effective dose values.

\subsection{Organ Doses}

The results of the critical organ doses are presented in Figures 3-7. As shown in Figure 3, the skin doses are above all limits for a shield thickness of $0.4 \mathrm{~g} \mathrm{~cm}^{-2}$, which is analogous to a spacesuit. Potential risks from skin exposures of this magnitude include moist desquamation and epilation. The U20 and BF18 spectra yield similar doses that are above the career limit, while BF10 doses are slightly above the 1-year limit. Dose estimates from all three spectrum models converge at thicknesses of $5 \mathrm{~g} \mathrm{~cm}^{-2}$ (comparable to a surface lander or rover) and greater, indicating that they provide adequate protection for the skin dose to be below permissible limits with no acute skin damage. Heart dose values are illustrated in Figure 4. Here BF18 dose values are slightly lower than values obtained from U20 and BF10. However, for all proton fluence spectra considered herein, any shielding above $0.4 \mathrm{~g} \mathrm{~cm}^{-2}$ will keep the heart dose limits below the 1-year limit, and an aluminum thickness around $20 \mathrm{~g} \mathrm{~cm}^{-2}$ is required to keep the heart doses below the 30-day limit. Figure 5 shows the lens dose values. At $0.4 \mathrm{~g} \mathrm{~cm}^{-2}, \mathrm{U} 20$ and BF18 dose values are very similar above the 1-year limit, while the BF10 dose value is between the 1-year and 30-day limits. At larger thicknesses, all input spectra yield doses within good agreement, with all doses being below the 30 day-limit. BFO doses, illustrated in Figure 6, exceed the 1 -year limit at $0.4 \mathrm{~g} \mathrm{~cm}^{-2}$ and the 30 -day limit until $10 \mathrm{~g} \mathrm{~cm}^{-2}$. Beyond that, the aluminum is thick enough for provide protection that keep the astronaut below the limits. Finally, none of the CNS dose values were above any limit for any spectrum, even with $0.4 \mathrm{~g} \mathrm{~cm}^{-2}$ of aluminum, as shown in Figure 7.

In general, the thinner the aluminum shield, the threshold energy for protons to penetrate that shield is lower. Since the U20 and BF18 spectra have significantly larger fluences than the BF10 spectrum at energies $10 \mathrm{~s}$ of MeV, more of the U20 and BF18 protons will penetrate the shield resulting in higher doses from them than for the BF10 spectrum. However, for thicker aluminum shields of $20 \mathrm{~g} \mathrm{~cm}^{-2}$ or more, incident protons with energies less than $\sim 100 \mathrm{MeV}$ are unable to penetrate the shield. From Figure 1, it is noted that the fluence spectra represented by the three parameterizations converge at $\sim 100 \mathrm{MeV}$ and become similar in magnitude. Hence, the doses produced by them will also converge to approximately the same values.

In summary, the crew doses and effective doses obtained using the proton fluence spectra from U20, BF18, and BF10 are very similar at all aluminum thicknesses with the 
exception of the thinnest aluminum shield considered herein. For spacesuit shielding, exposure to an entire event of the magnitude of the February 1956 would result in skin damage. However, an aluminum shield of $20 \mathrm{~g} \mathrm{~cm}^{-2}$ would be sufficient to keep the critical organ doses below the permissible limits from this event.

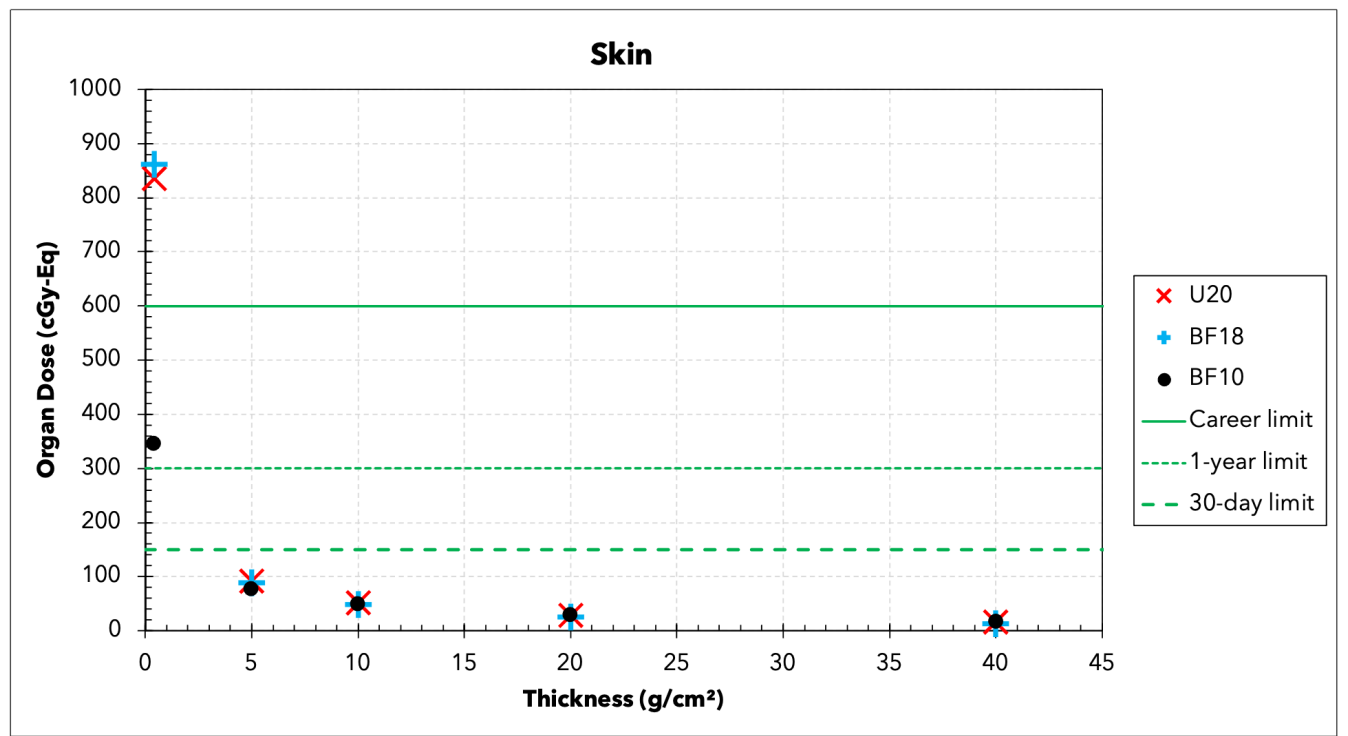

Figure 3. The skin dose from U20, BF18, and BF10 February 1956 event spectra for various aluminum thicknesses. NASA's permissible career, 1-year, and 30-day skin dose limits are included in the plot.

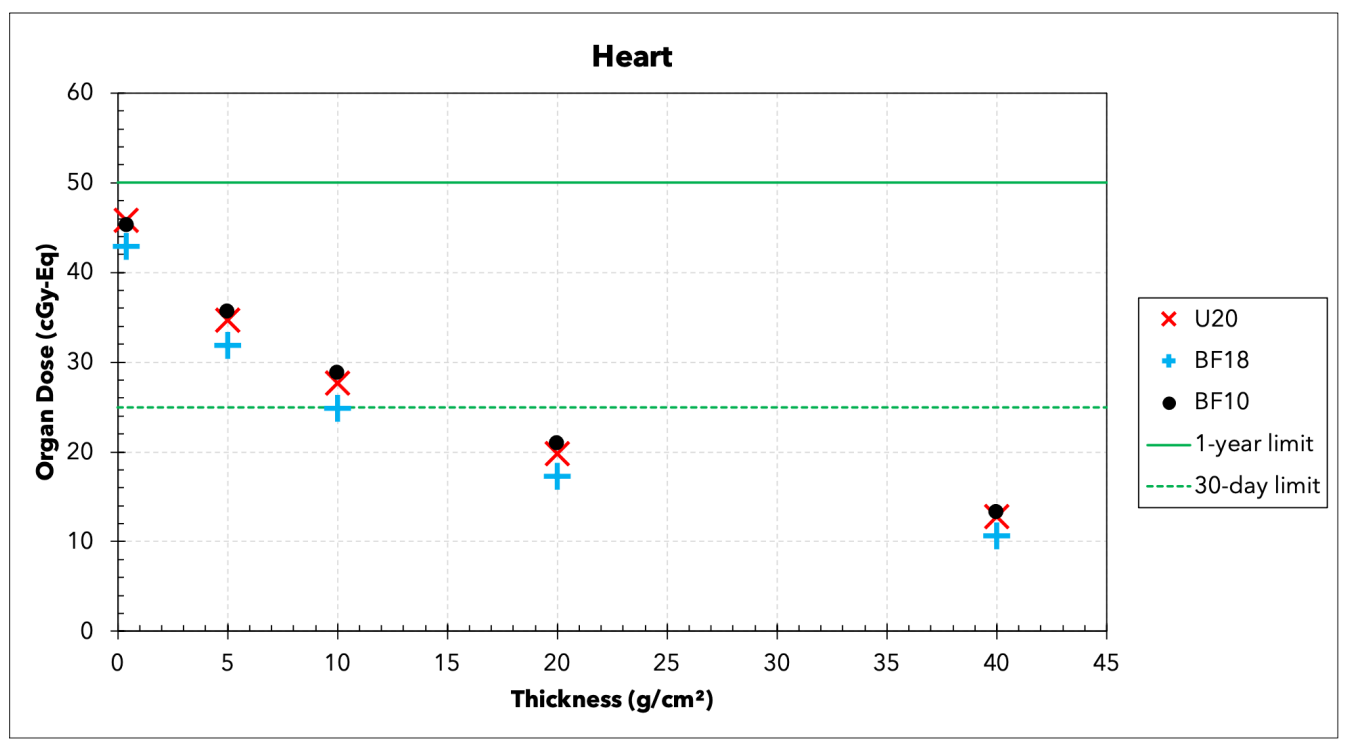

Figure 4. The heart dose from U20, BF18, and BF10 February 1956 event spectra for various aluminum thicknesses. NASA's permissible 1-year and 30-day heart dose limits are included in the plot. The career limit (100 cGy-Eq) is above the maximum obtained dose values. 


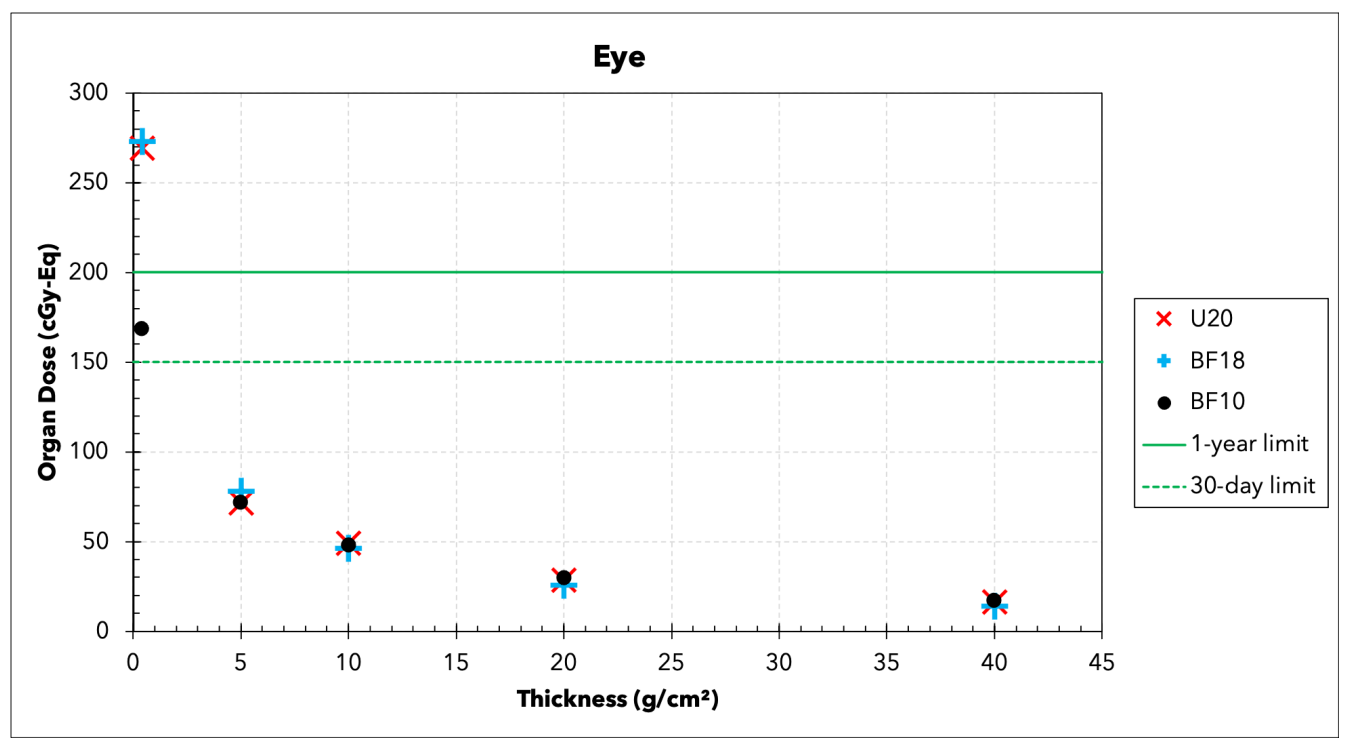

Figure 5. The lens dose from U20, BF18, and BF10 February 1956 event spectra for various aluminum thicknesses. NASA's permissible 1-year and 30-day lens dose limits are included in the plot. The career limit (400 cGy-Eq) is above the maximum obtained dose values.

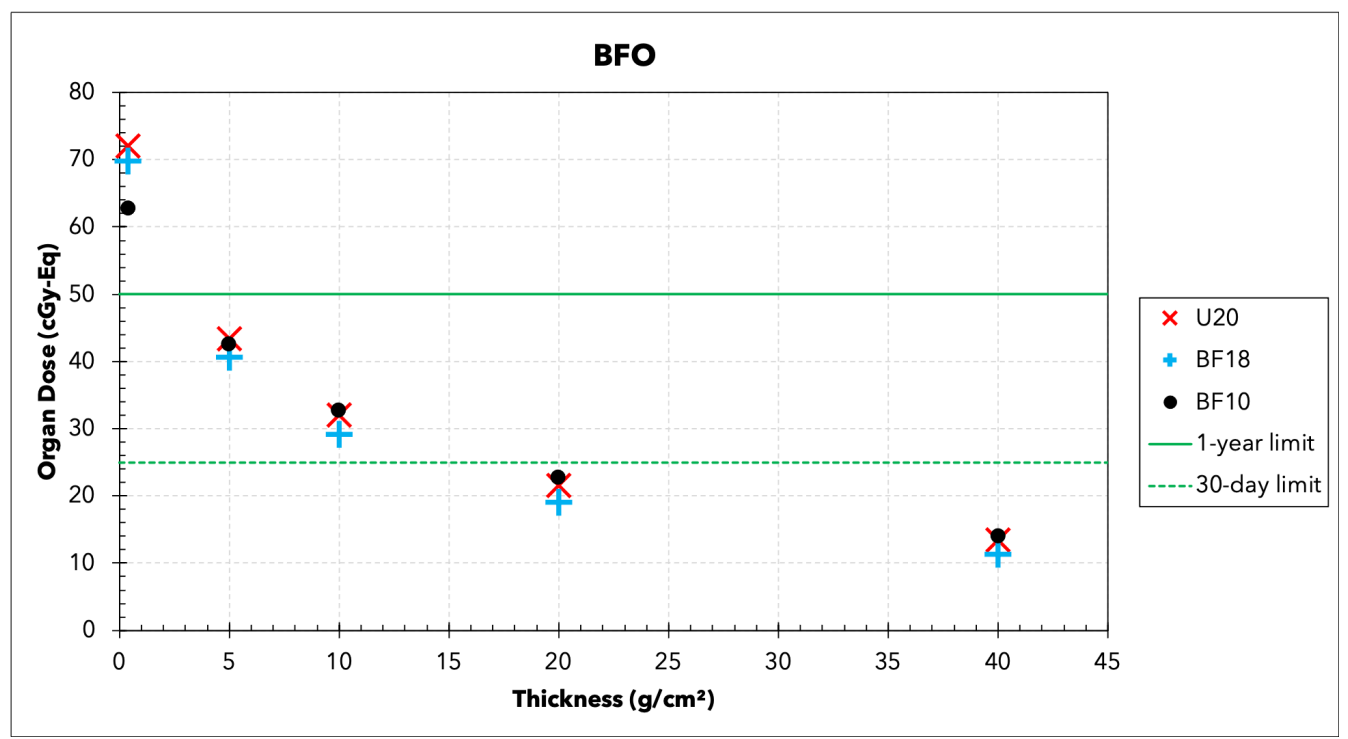

Figure 6. The BFO dose from U20, BF18, and BF10 February 1956 event spectra for various aluminum thicknesses. NASA's permissible 1-year and 30-day BFO dose limits are included in the plot. 


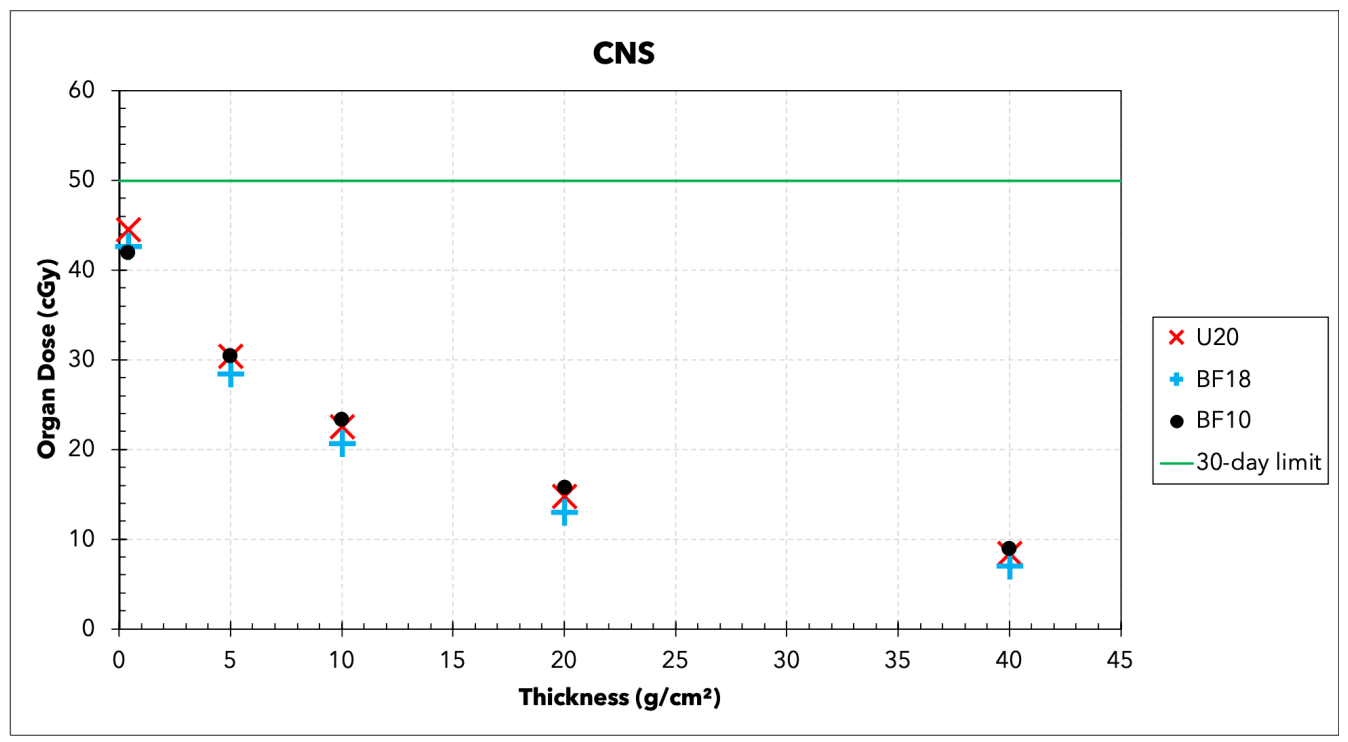

Figure 7. The CNS dose from U20, BF18, and BF10 February 1956 event spectra for various aluminum thicknesses. NASA's permissible 30-day lens dose limits are included in the plot. Note that the maximum obtained dose values are below the 30-day limit.

\section{Conclusions and Future Work}

In this work, we present the biological risk of a February 1956 category event on a mission in cis-Lunar space. Three different parametrizations approximating the proton fluence spectra of the event, BF10, BF18, and U20, were transported in OLTARIS to compare the critical organ doses received by female astronauts protected by aluminum shield with varying thicknesses. Although the doses estimated by the three models disagree by varying factors at very thin shields, they tend to produce converging results with only slight differences for thicker shields. The results show that the minimum thickness of aluminum required to keep effective dose and critical organ doses below NASA's 30-day limits for a February 1956 category event is $20 \mathrm{~g} \mathrm{~cm}^{-2}$, with the heart being the most sensitive organ. They also show that thicknesses comparable to a spacesuit might not protect against severe health consequences, especially for the skin, since such large doses are likely to results in some skin damage (e.g., moist desquamation). Future work will include estimating doses for the February 1956 event in different regions of space, like the lunar surface and surface of Mars, by incorporating additional updated parametrizations like the one provided by [20]. It also includes estimating organ doses and effective doses for other more extreme solar particle events in cis-Lunar space, such as the 774/775 AD and 993/994 AD events, along with the upper limits of our star [21].

Author Contributions: Conceptualization, F.A.Z. and L.W.T.; methodology, F.A.Z. and L.W.T.; software, L.W.T.; formal analysis, F.A.Z.; writing-original draft preparation, F.A.Z. and L.W.T.; writingreview and editing, F.A.Z. and L.W.T.; visualization, F.A.Z. All authors have read and agreed to the published version of the manuscript.

Funding: This research received no external funding.

Institutional Review Board Statement: Not applicable.

Informed Consent Statement: Not applicable.

Data Availability Statement: This study does not report any data.

Conflicts of Interest: The authors declare no conflict of interest. 


\section{References}

1. Rishbeth, H.; Shea, M.; Smart, D. The solar-terrestrial event of 23 February 1956. Adv. Space Res. 2009, 44, 1096-1106. [CrossRef]

2. Meyer, P.; Parker, E.; Simpson, J. Solar Cosmic Rays of February, 1956 and Their Propagation through Interplanetary Space. Phys. Rev. 1956, 104, 768-783. [CrossRef]

3. Schaefer, H. Extra-Atmospheric Cosmic Ray Dosage During the Large Solar Flare of 23 February 1956. Sci. Am. Assoc. Adv. Sci. 1958, 127, 186-187. [CrossRef] [PubMed]

4. Townsend, L.; Wilson, J.; Shinn, J.; Curtis, S. Human exposure to large solar particle events in space. Adv. Space Res. 1992, 12, 339-348. [CrossRef]

5. Townsend, L.; Cucinotta, F.; Shinn, J.; Wilson, J. Risk Analyses for the Solar Particle Events of August through December 1989. Radiat. Res. 1992, 130, 1-6. [CrossRef] [PubMed]

6. McCracken, K.; Dreschhoff, G.; Zeller, E.; Smart, D.; Shea, M. Solar cosmic ray events for the period 1561-1994: 1. Identification in polar ice, 1561-1950. J. Geophys. Res. Space Phys. 2001, 106, 21585-21598. [CrossRef]

7. Miyake, F.; Nagaya, K.; Masuda, K.; Nakamura, T. A signature of cosmic-ray increase in AD 774-775 from tree rings in Japan. Nature 2012, 486, 240-242. [CrossRef] [PubMed]

8. Usoskin, I.; Kovaltsov, G. Occurrence of extreme solar particle events: Assessment from historical proxy data. Astrophys. J. 2012, 757, 92. [CrossRef]

9. O'Hare, P.; Mekhaldi, F.; Adolphi, F.; Raisbeck, G.; Aldahan, A.; Anderberg, E.; Beer, J.; Christl, M.; Fahrni, S.; Synal, H.; et al. Multiradionuclide evidence for an extreme solar proton event around 2610 B.P. (around 660 BC). Proc. Natl. Acad. Sci. USA 2019, 116, 5961-5966. [CrossRef] [PubMed]

10. Wolff, E.; Bigler, M.; Curran, M.; Dibb, J.; Frey, M.; Legrand, M.; McConnell, J. The Carrington event not observed in most ice core nitrate records: Ice core nitrate and Carrington event. Geophys. Res. Lett. 2012, 39, 8. [CrossRef]

11. Usoskin, I. A History of Solar Activity over Millennia. Living Rev. Sol. Phys. 2013, 10, 1. [CrossRef]

12. Cliver, E.; Hayakawa, H.; Love, J.; Neidig, D. On the Size of the Flare Associated with the Solar Proton Event in 774 AD. Astrophys. J. 2020, 903, 1. [CrossRef]

13. Tylka, A.J.; Dietrich, W.; Atwell, W. Band function representations of solar proton spectra in ground-level events. 38th COSPAR Sci. Assem. 2010, 38, 4.

14. Usoskin, I.; Kromer, B.; Ludlow, F.; Beer, J.; Friedrich, M.; Kovaltsov, G.; Solanki, S.; Wacker, L. The AD775 cosmic event revisited: The Sun is to blame. Astron. Astrophys. 2013, 552, L3. [CrossRef]

15. Townsend, L.; Porter, J.; de Wet, W.; Smith, W.; McGirl, N.; Heilbronn, L.; Moussa, H. Extreme solar event of AD775: Potential radiation exposure to crews in deep space. Acta Astronaut. 2016, 123, 116-120. [CrossRef]

16. Raukunen, O.; Vainio, R.; Tylka, A.; Dietrich, W.; Jiggens, P.; Heynderickx, D.; Dierckxsens, M.; Crosby, N.; Ganse, U.; Siipola, R. Two solar proton fluence models based on ground level enhancement observations. J. Space Weather Space Clim. 2018, 8, A04. [CrossRef]

17. Usoskin, I.; Koldobskiy, S.; Kovaltsov, G.; Rozanov, E.; Sukhodolov, T.; Mishev, A.; Mironova, I. Revisited reference solar proton event of 23 February 1956: Assessment of the cosmogenic-isotope method sensitivity to extreme solar events. J. Geophys. Res. Space Phys. 2020, 125, e2020JA027921. [CrossRef]

18. Cucinotta, F.; Schimmerling, W.; Wilson, J.; Peterson, L.; Badhwar, G.; Saganti, P.; Dicello, F. Space Radiation Cancer Risks and Uncertainties for Mars Missions. Radiat. Res. 2001, 156, 682-688. [CrossRef]

19. NASA. 1:Crew Health. In NASA Space Flight Human-System Standard Volume 1, Revision A; National Aeronautics and Space Administration: Washington, DC, USA, 2014.

20. Koldobskiy, S.; Raukunen, O.; Vainio, R.; Kovaltsov, G.; Usoskin, I. New reconstruction of event-integrated spectra (spectral fluences) for major solar energetic particle events. Astron. Astrophys. 2021, 647, A132. [CrossRef]

21. Herbst, K.; Papaioannou, A.; Banjac, S.; Heber, B. From solar to stellar flare characteristics-On a new peak size distribution for G-, K-, and M-dwarf star flares. Astron. Astrophys. 2019, 621, A67. [CrossRef] 